\title{
Diverse Pattern of Cytokine Production, their Functional Association and mRNA Expression in Tuberculosis Patients with Diabetes Mellitus and their Household Contacts
}

\author{
Meenakshi $\mathrm{P}^{1}$, Ramya $\mathrm{S}^{1}$, Madhavi Latha $\mathrm{A}^{1}$, Lavanya $\mathrm{J}^{1}$ and Sumanlatha $\mathbf{G}^{1,2^{*}}$ \\ ${ }^{1}$ Department of Immunology, Bhagwan Mahavir Medical Research Center, India \\ ${ }^{2}$ Department of Genetics, Osmania University, India
}

\begin{abstract}
Cytokine genes are associated with their altered production and play a significant role in tuberculosis patients with diabetes mellitus and their household contacts. We aimed to study the influence of IL-1 $\beta$ and IL-6 gene polymorphisms on cytokine gene production and to evaluate their mRNA expression in M.tbAg85A stimulated culture supernatants of tuberculosis patients with diabetes mellitus, pulmonary tuberculosis patients, household contacts and diabetes individuals. Enzyme linked immunosorbent assay was used to estimate cytokine production in the culture supernatants and TRIZOL method for mRNA expression. Cytokine production was low in all the subjects when compared to the healthy controls and IL-6 levels increased with treatment. The CC genotype of IL-6 -174 G/C was associated with its low production in household contacts of tuberculosis patients with diabetes mellitus and pulmonary tuberculosis patients. The mRNA expression of IL- $1 \beta$ increased and that of IL- 6 decreased in tuberculosis patients with diabetes mellitus, while that of IL-6 decreased with treatment in pulmonary tuberculosis patients; however, there was no significant difference in the household contacts. The cytokine levels were almost similar in patients and their household contacts at the time of diagnosis suggesting that even the household contacts might be infected thus aiding in protecting the high-risk individuals by their prior identification.
\end{abstract}

Keywords: Antigen 85A; Cytokine gene correlation; mRNA expression; Household contacts

Abbreviations: TBDM: Tuberculosis with Diabetes Mellitus; HHC: House-Hold Contacts; HC: Healthy Controls; IL: Interleukin; ROC: Receiver Operating Characteristic

\section{Introduction}

Tuberculosis (TB) an infectious disease caused by Mycobacterium tuberculosis (M.tb) is the leading cause of death worldwide [1]. Several co-morbidities, one of which is type 2 diabetes mellitus (DM) increased the risk of susceptibility to TB by threefold [2,3]. It is predicted that globally $15 \%$ of TB cases are projected to be attributable to DM thus becoming an increasingly important factor challenging TB control $[4,5]$. The immune response variation in DM patients against M.tb makes them more vulnerable to infection or progression towards active TB disease and thereby diminished treatment response [6,7]. Diabetes alters immunity to tuberculosis, leading to higher baseline mycobacterial burdens and longer times to culture conversion with treatment resulting in higher rate of relapse [8]. Nevertheless, the fundamental biological mechanisms remain largely unidentified $[9,10]$.

The infection is exclusively transmitted from pulmonary TB patients through aerosol. Contact investigation among TB patients is a systematic evaluation to identify active disease or latent M.tb infection (LTBI) among household members of TB patients and to interrupt the disease transmission [11-14]. The risk of transmission is maximum when index case is sputum smear positive, in overcrowded living conditions, a higher density of bacilli in respiratory secretions and extent of lung fields involved $[15,16]$. Henceforth, those living in the same household are at higher risk than the usual contacts.

TB and DM patients have been associated with dysregulated cytokine responses towards M.tb. Pro-inflammatory cytokines are necessary for protection against $M . t b$, anti-inflammatory cytokines may counteract these effects. Inflammatory cytokines like IL- $1 \beta$ and IL- 6 may play a major role in the pathogenesis of TB and DM that are produced upon stimulation of peripheral blood mononuclear cells (PBMC) with M.tb antigen 85A [17]. A major portion of the secreted proteins in M.tb is formed by the Ag85 complex, a $30-$ to $32-\mathrm{kDa}$ family of three proteins (Ag85A, Ag85B and Ag85C) that is important in relation to their particular role in the interaction between the bacilli and the infected host. It induces strong T-cell proliferation and IFN- $\gamma$ production in M.tb infected individuals.

IL-1 $\beta$ secreted by infected macrophages, in particular, is implicated in granuloma formation signaling and its deficiency leads to induced $M . t b$ growth at the site of infection in mice [18]. The majority of TB patients with infiltrative lesions on chest radiographs also expressed significantly elevated IL- $1 \beta$ and TNF- $\alpha$ compared to the baseline values. The amount of IL- $1 \beta$ secreted to the microenvironment is regulated at the mRNA and protein level. It mediates a local inflammatory response conferring resistance to infection by regulating the expression of several other inflammatory genes [19]. The pro-inflammatory cytokine IL- $1 \beta$ response is strongly induced by $M . t b$ and is encoded by the polymorphic genes. IL- $1 \beta+3954 \mathrm{C}>\mathrm{T}$ and $-511 \mathrm{C}>\mathrm{T}$ polymorphisms and their correlation has been associated with TB. It is mostly involved in the early recruitment of inflammatory cells to M.tb or PPD stimulated granulomas and in establishing anti-mycobacterial adaptive immunity [20].

*Corresponding author: Sumanlatha G, Department of Immunology, Bhagwan Mahavir Medical Research Centre, India, Tel: 040- 23497303; E-mail: sumanlathag@yahoo.com, sumanlathag26@gmail.com

Received March 21, 2017; Accepted June 26, 2017; Published July 03, 2017

Citation: Meenakshi P, Ramya S, Madhavi Latha A, Lavanya J, Sumanlatha G (2017) Diverse Pattern of Cytokine Production, their Functional Association and mRNA Expression in Tuberculosis Patients with Diabetes Mellitus and their Household Contacts. J Microb Biochem Technol 9:143-150. doi: 10.4172/19485948.1000358

Copyright: (c) 2017 Meenakshi P, et al. This is an open-access article distributed under the terms of the Creative Commons Attribution License, which permits unrestricted use, distribution, and reproduction in any medium, provided the original author and source are credited. 
Citation: Meenakshi P, Ramya S, Madhavi Latha A, Lavanya J, Sumanlatha G (2017) Diverse Pattern of Cytokine Production, their Functional Association and mRNA Expression in Tuberculosis Patients with Diabetes Mellitus and their Household Contacts. J Microb Biochem Technol 9:143-150. doi: 10.4172/1948-5948.1000358

IL-6 is a pleiotropic cytokine with a wide range of humoral and cellular immune effects relating to inflammation, host defense, tissue injury and is produced in response to several mediators like IL- 1, IFN- $\gamma$ and TNF. In mycobacterial infection, mice deficient with IL-6 exhibit an altered immune response and thereby increased susceptibility to M.tb infection when compared to the wild-type mice [21]. IL-6 expressed by a variety of cell lineages with diverse functions, contributes to the differentiation and activation of the cells leading to an immune response [22]. A common polymorphism in the IL-6 gene promoter $-174 \mathrm{G}>\mathrm{C}$ regulates transcription in response to lipopolysaccharides while that at $-572 \mathrm{G}>\mathrm{C}$ affects IL-6 gene transcription and its serum levels $[23,24]$.

Hence, we designed the present study to understand the IL- $1 \beta$ and IL-6 cytokine production pattern, their functional association and mRNA expression in PBMC of tuberculosis patients with and without diabetes mellitus and their household contacts.

\section{Materials and Methods}

\section{Study population}

We enrolled 300 subjects including tuberculosis patients with diabetes mellitus (TBDM), their household contacts (TBDM HHC), pulmonary tuberculosis patients (PTB), their household contacts (PTB $\mathrm{HHC})$, diabetes mellitus patients (DM) and healthy controls without clinical complaints (HC), 50 in each category, attending Bhagwan Mahavir Medical Research Center (BMMRC) under the public private mix directly observed treatment shortcourse program (PPM-DOTS). PTB diagnosis was confirmed by sputum smears or culture positivity for M.tb or by clinical-epidemiologic data compatible with active TB. Diabetes was confirmed based on the blood sugar levels. Body mass index (BMI) was analyzed in all the subjects. Tuberculin Skin Test (TST) was performed in all the subjects except in the DM and HC, wherein $5 \mathrm{TU}$ purified protein derivative (PPD) was injected into the left forearm and the reading was noted after $48 \mathrm{~h}$. An induration $>10 \mathrm{~mm}$ was considered positive. Patients concurrent with other active granulomatous diseases or HIV were excluded. TBDM and PTB patients received six months treatment. For the evaluation of immunologic function, patients' samples were collected based on the anti-TB treatment timeline, defined as 0M: after diagnosis before start of treatment; 4M: with four months of treatment; $6 \mathrm{M}$ : with six months of treatment and $12 \mathrm{M}$ after six months of treatment completion. All the subjects agreed to participate in the study, after study clarification and written informed consent.

\section{Enzyme linked immuno-sorbent assay (ELISA), genotyping and reverse transcriptase PCR (RT-PCR)}

Stimulation assays on PBMCs by Ag85A was already discussed previously [25]. Culture supernatants were obtained from the M.tb stimulated PBMC of all the subjects and the cytokines present in these supernatants were analyzed by ELISA using the kits available from $\mathrm{BD}$ biosciences.

In the present study, four Single Nucleotide Polymorphisms (SNPs) were analyzed: IL- $1 \beta+3954 \mathrm{C}>\mathrm{T}$, IL- $1 \beta-511 \mathrm{C}>\mathrm{T}$, IL- $6-174 \mathrm{G}>\mathrm{C}$ and IL-6 -572G $>$ C. For genotyping, $2 \mathrm{ml}$ blood was drawn, collected in EDTA coated tubes, DNA isolated by Flexigene DNA isolation kit, quantification and purity determined on a spectrophotometer (NanoDrop 2000 Thermo Fisher Scientific). Amplification of the genomic regions of interest was performed by PCR using 20-50 ng of DNA, recombinant Taq DNA polymerase, $0.2 \mathrm{mM}$ of each dNTP (deoxynucleotide-adenine, guanine, thymine or cytosine-triphosphate), 0.3-1 $\mathrm{mM}$ concentration of each of the specific primers, appropriate buffer and ultrapure water. The primer sequences and PCR conditions were shown in Tables 1 and 2.

cDNA was synthesized from the mRNA isolated from the stimulated PBMCs and amplified using the mRNA primers (Table 3). The IL-1 $\beta$, IL- 6 and the housekeeping gene glyceraldehyde-3phosphate dehydrogenase (GAPDH) expression was carried out using SYBR green in iCycler IQ multicolor real-time detection system (Bio$\mathrm{Rad})$. Amplifications and thermal-cycler parameters were followed according to the manufacturer's directions. The delta-delta method (i.e., comparative ct $[\Delta \mathrm{ct}]$ method) was used for quantitative analysis of gene expression. The results were normalized to those for GAPDH in the same sample and were expressed as fold increase. Gene expressions were determined based on results of stimulated cells as a fold change compared with basal levels in unstimulated cells.

\section{Statistical analysis}

Comparisons between different genotypes in the control and patient

\begin{tabular}{|c|c|c|c|}
\hline Gene Chromosome & SNP Property & PCR Primers & PCR Product size \\
\hline $\begin{array}{l}\text { IL-1 } \beta+3954 C>T \\
\text { Chr } 2\end{array}$ & Intron & $\begin{array}{l}\text { Forward primer }-5^{\prime} \text {-GTT GTC ATC AGA CTT TGA CC-3' } \\
\text { Reverse primer }-5^{\prime} \text {-TTC AGT TCA TAT GGA CCA GA-3' }\end{array}$ & $\begin{array}{l}\text { Taq } 1 \\
349 \text { bp,135 bp, } 114 \text { bp }\end{array}$ \\
\hline $\begin{array}{l}\text { IL-1 } \beta-511 C>T \\
\text { Chr } 2\end{array}$ & Promoter & $\begin{array}{l}\text { Left primer }-5 \text { '-TGG CAT TGA TCT GGT TCA TC-3', } \\
\text { Right primer -5'-GTT TAG GAA TCT TCC CAC TT-3' }\end{array}$ & $\begin{array}{l}\text { Ava } 1 \\
305 \text { bp,190 bp,114 bp }\end{array}$ \\
\hline $\begin{array}{l}\text { IL-6 -174G>C } \\
\text { Chr } 7\end{array}$ & Promoter & $\begin{array}{l}\text { Common primer -5'-GAGCTTCTCTTTCGT TC-3' } \\
\text { Right primer -5'-CTAGTTGTGTCTTGCC-3' } \\
\text { Left primer -5'-CCCTAGTTGTGTCCTGCG-3' }\end{array}$ & $\begin{array}{l}\text { ARMS } \\
234 \text { bp }\end{array}$ \\
\hline $\begin{array}{l}\text { IL-6 }-572 \mathrm{G}>\mathrm{C} \\
\mathrm{Chr} 7\end{array}$ & Promoter & $\begin{array}{l}\text { Right primer -5'-GGAGACGCCTTGAAGTAACTGC-3' } \\
\text { Left primer -5'-GAGTTTCCTCTGACTCCATCGCAG-3' }\end{array}$ & $\begin{array}{l}\text { Fok } 1 \\
163 \mathrm{bp}\end{array}$ \\
\hline
\end{tabular}

Table 1: Primer sequences of IL-1 $\beta$ and IL- 6 cytokine genes.

\begin{tabular}{|c|c|c|c|c|c|}
\hline Cytokine & Initial Denaturation & Annealing & Extension & Final Extension & No. Of cycles \\
\hline $\mathrm{IL}-1 \beta+3954 \mathrm{C}>\mathrm{T}$ & $\begin{array}{c}95^{\circ} \mathrm{C}-4 \min \\
95^{\circ} \mathrm{C}-30 \mathrm{~s}\end{array}$ & $59^{\circ} \mathrm{C}-30 \mathrm{~s}$ & $72^{\circ} \mathrm{C}-30 \mathrm{~s}$ & $72^{\circ} \mathrm{C}-4 \min$ & 33 \\
\hline $\mathrm{IL}-1 \beta-511 \mathrm{C}>\mathrm{T}$ & $\begin{array}{l}94^{\circ} \mathrm{C}-5 \min \\
94^{\circ} \mathrm{C}-1 \mathrm{~min}\end{array}$ & $55^{\circ} \mathrm{C}-1 \mathrm{~min}$ & $72^{\circ} \mathrm{C}-1 \mathrm{~min}$ & $72^{\circ} \mathrm{C}-7 \mathrm{~min}$ & 45 \\
\hline IL-6 -174G>C & $\begin{array}{l}95^{\circ} \mathrm{C}-4 \mathrm{~min} \\
95^{\circ} \mathrm{C}-30 \mathrm{~s}\end{array}$ & $60^{\circ} \mathrm{C}-30 \mathrm{~s}$ & $74^{\circ} \mathrm{C}-30 \mathrm{~s}$ & $74^{\circ} \mathrm{C}-7 \mathrm{~min}$ & 35 \\
\hline IL-6 -572G>C & $\begin{array}{c}94^{\circ} \mathrm{C}-4 \min \\
95^{\circ} \mathrm{C}-40 \mathrm{~s}\end{array}$ & $55^{\circ} \mathrm{C}-40 \mathrm{~s}$ & $72^{\circ} \mathrm{C}-1 \mathrm{~min}$ & - & 35 \\
\hline
\end{tabular}

Table 2: PCR conditions of IL-1 $\beta$ and IL-6 cytokine genes. 
Citation: Meenakshi P, Ramya S, Madhavi Latha A, Lavanya J, Sumanlatha G (2017) Diverse Pattern of Cytokine Production, their Functional Association and mRNA Expression in Tuberculosis Patients with Diabetes Mellitus and their Household Contacts. J Microb Biochem Technol 9:143-150. doi: 10.4172/1948-5948.1000358

groups were made using Mann-Whitney Test with two-tail value. For the analytical comparison between the time points of the treatment (0M, $4 \mathrm{M}, 6 \mathrm{M}$ and $12 \mathrm{M})$, a Friedman test was used to verify which time point differed from the other, a Dunn's multiple comparisons test was applied as a post-test. Results were considered significant when $\mathrm{p}<0.05$. Tests were performed using Graph Pad Prism version 5.00 for Windows, Graph Pad Software (San Diego, CA, USA). The IL-1 $\beta$ and IL-6 cytokine production in $M . t b$ stimulated culture supernatants were studied in 50 cases of each TBDM, PTB, TBDM HHC, PTB HHC, DM and HC and were correlated with their cytokine gene polymorphisms. TBDM, PTB, TBDM HHC, PTB HHC, 25 each were followed at different intervals $0 \mathrm{M}, 4 \mathrm{M}, 6 \mathrm{M}$ and $12 \mathrm{M}$ for the IL- $1 \beta$ and IL- 6 production and 5 cases were followed for their mRNA expression.

\section{Results}

\section{Cytokine production and functional correlation}

Cytokine production of IL- $1 \beta$ was significantly low in TBDM $(52.78$ $\pm 33.93, \mathrm{p}=0.002)$, TBDM HHC $(54.94 \pm 34.92, \mathrm{p}=0.012)$, РTB (58.18 $\pm 40.43, \mathrm{p}=0.012)$, PTB HHC $(54.38 \pm 37.81, \mathrm{p}=0.02)$ and DM $(55.81 \pm$ $40.87, \mathrm{p}=0.02)$ when compared to HC $(73.57 \pm 30.91) \mathrm{pg} / \mathrm{ml}$. Similarly IL-6 production was low in TBDM, TBDM HHC, PTB, PTB HHC and DM compared to HC $(82.76 \pm 29.92,91.95 \pm 34.51,82.13 \pm 28.23,113.3$ $\pm 73.5,97.23 \pm 43.46,171.2 \pm 40.19 \mathrm{pg} / \mathrm{ml}$ respectively with statistical significance of $\mathrm{p}=0.0001$ in each category). Statistical significance was observed with IL- 6 production in TBDM vs DM at $\mathrm{p}=0.044$ and in PTB vs PTB HHC at $p=0.005$. Almost similar IL- $1 \beta$ was secreted by TBDM, PTB, TBDM HHC, PTB HHC during follow-up. High levels of IL-6 were secreted at $12 \mathrm{M}$ by TBDM $(99.57 \pm 34.91, \mathrm{p}=0.02)$; at $4 \mathrm{M}(107.0$

\begin{tabular}{|c|l|c|}
\hline GENE & \multicolumn{1}{|c|}{ Primer sequence } & Amplicon size \\
\hline IL-1 $\beta$ & $\begin{array}{l}\text { F- CCACAGACCTTCCAGGAGAATG } \\
\text { R- GTGCAGTTCAGTGATCGTACAGG }\end{array}$ & $148 \mathrm{bp}$ \\
\hline IL-6 & $\begin{array}{l}\text { F- TACCCCCAGGAGAAGATTCC } \\
\text { R- TTTTCTGCCAGTGCCTCTTT }\end{array}$ & $175 \mathrm{bp}$ \\
\hline GAPDH & $\begin{array}{l}\text { F- GCCAATCAATGACCCCTTCATT } \\
\text { R-TTGACGGTGCCATGGAATTT }\end{array}$ & $320 \mathrm{bp}$ \\
\hline
\end{tabular}

Table 3: mRNA primer sequences of IL-1 $\beta, I L-6$ and GAPDH for expression analysis $\pm 35.68, \mathrm{p}=0.0091)$ and $6 \mathrm{M}(103.8 \pm 48.0, \mathrm{p}=0.0034)$ by PTB when compared to that at $0 \mathrm{M}$ (Figures 1 and 2).

Results for the IL- $1 \beta+3954 \mathrm{C}>\mathrm{T}$ SNP showed that TBDM and TBDM HHC with CC genotype, PTB HHC and DM with CT genotype presented low levels of IL- $1 \beta$ when compared to the HC with TT genotype. TBDM, PTB, HC with CT genotype; HHC and DM with TT genotype presented high levels of IL-1 $\beta$. Statistical significance was observed with CC $(58.3 \pm 42.7)$ vs. TT $(92.2 \pm 25.3)$ at $\mathrm{p}=0.043$ and with CT $(46.5 \pm 38.6)$ vs. TT $(92.2 \pm 25.3)$ at $\mathrm{p}=0.009$ in DM. At $-511 \mathrm{C}>\mathrm{T}$ variant, TBDM, PTB HHC and HC with TT genotype; TBDM HHC with CT genotype and PTB and DM patients with CC genotype produced low levels of IL-1 $\beta$. TBDM with CT genotype, HHC and HC with CC genotype, PTB and DM with TT genotype produce high levels of IL-1 $\beta$. For IL-6 -174G >C variant, TBDM, TBDM HHC, DM with CC genotype, PTB, PTB HHC and HC with GG genotype produce low IL-6 levels. In HC, statistical significance was observed at $\mathrm{p}=0.03$ with respect to CC vs. GG $(186.7 \pm 51.5$ vs. $150.8 \pm 36.0)$ genotype. TBDM, TBDM HHC and DM with GG genotype, PTB, PTB HHC and HC with CC genotype produce high levels of IL-6. At IL-6 -572 G>C, TBDM, HHC and DM with GC genotype, PTB and HC with CC genotype produce low levels of IL-6. While TBDM patients with CC genotype, TBDM, PTB, HHC, DM and HC with GG genotype produce high levels of IL-6 (Figures 3 and 4).

Upon Receiver Operating Characteristic (ROC) curve analysis, the sensitivity and specificity of IL- $1 \beta$ and IL- 6 cytokine gene markers were computed and ROC curves were constructed in the TBDM, TBDM HHC, PTB, PTB HHC, DM vs HC where the Area under the curve (AUC) with statistical significance was determined at 95\% confidence interval. The cut-off value is derived and the sensitivity, specificity determined to identify the individuals risk with respect to the cytokine gene marker. AUC was more for IL-6 $(0.97,0.944,0.96,0.75,0.90)$ and that of IL- $1 \beta(0.68,0.65,0.60,0.65,0.63)$ was less in TBDM, TBDM HHC, PTB, PTB HHC and DM respectively when compared to HC indicating that the test was performed more accurately in IL-6 with statistical significance $(\mathrm{p}<0.0005)$. The cut-off value, sensitivity and specificity were the best for IL- 6 that were $125.56 \mathrm{pg} / \mathrm{ml}, 90$ and 4 in TBDM, $119.93 \mathrm{pg} / \mathrm{ml}, 92$ and 24 in TBDM HHC, $13.19 \mathrm{pg} / \mathrm{ml}, 88$ and 6
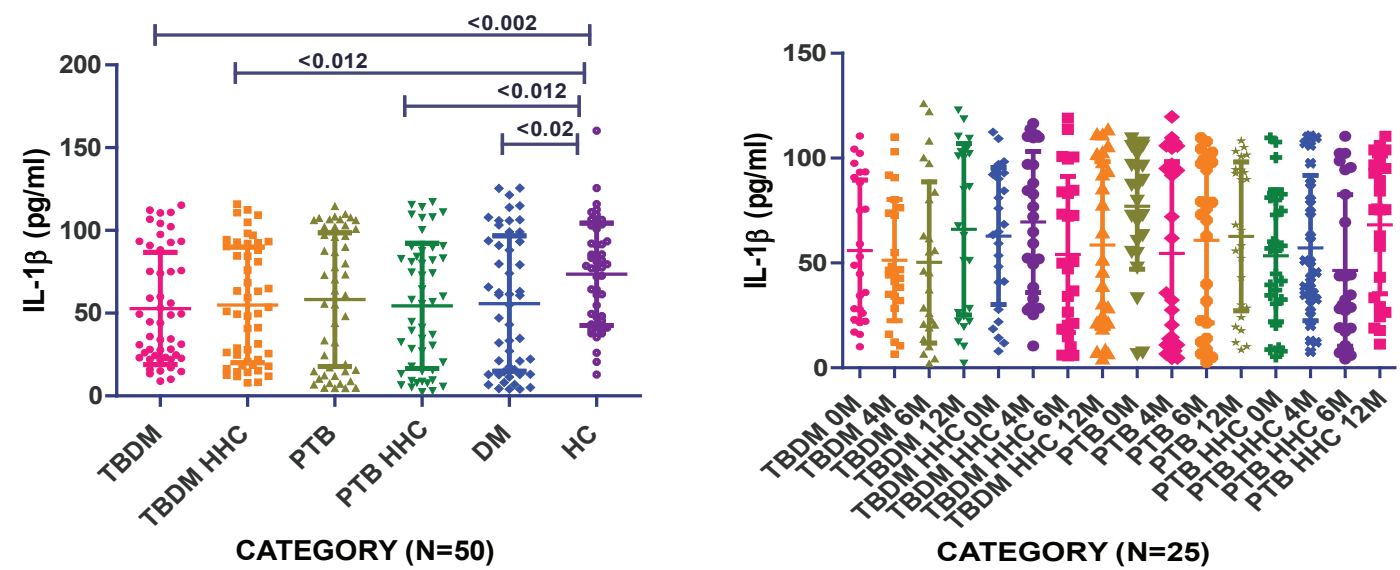

Figure 1: IL-1 $1 \beta$ levels in M.tb Ag85A stimulated culture supernatants of TBDM, PTB patients, their HHC, DM and HC and during follow-up of TBDM, PTB and their HHC.

Bars indicate the mean and SD for each group. Horizontal lines indicate a statistically significant difference between groups. Differences between the groups were analyzed by Mann-Whitney $U$ test

${ }^{*} p=0.05$ was considered statistically significant 
Citation: Meenakshi P, Ramya S, Madhavi Latha A, Lavanya J, Sumanlatha G (2017) Diverse Pattern of Cytokine Production, their Functional Association and mRNA Expression in Tuberculosis Patients with Diabetes Mellitus and their Household Contacts. J Microb Biochem Technol 9:143-150. doi: 10.4172/1948-5948.1000358
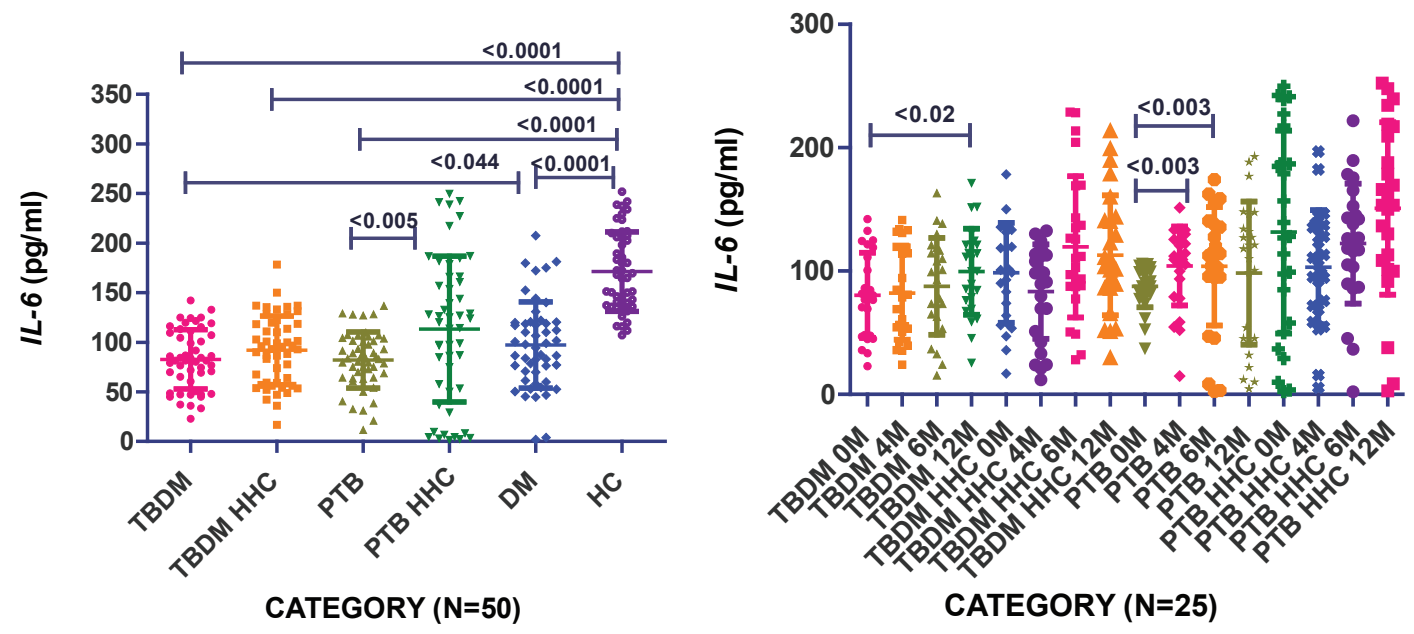

Figure 2: IL-6 levels in M.tb Ag85A stimulated culture supernatants of TBDM, PTB patients, their HHC, DM and HC and during follow-up of TBDM, PTB patients and their HHC.

Bars indicate the mean and SD for each group. Horizontal lines indicate a statistically significant difference between groups. Differences between the groups were analyzed by Mann-Whitney $U$ test

${ }^{*} \mathrm{p}=0.05$ was considered statistically significant
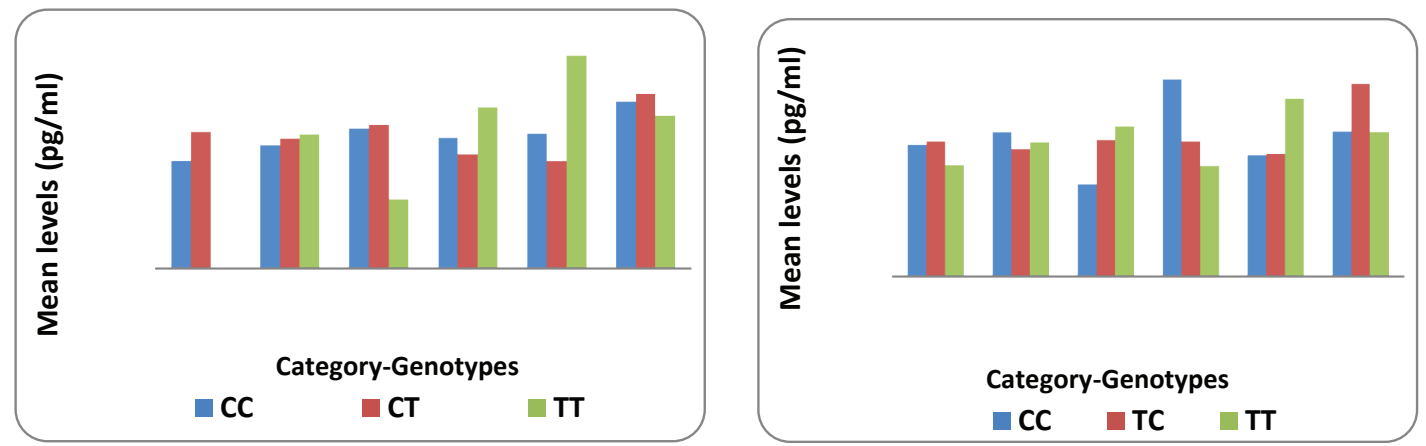

TBDM: Tuberculosis with Diabetes Mellitus; HHC: Household Contacts; PTB: Pulmonary Tuberculosis; DM: Diabetes Mellitus; HC: Healthy Controls

Figure 3: IL-1 $\beta+3954 \mathrm{C}>\mathrm{T}$ and $-511 \mathrm{C}>\mathrm{T}$ genotypes related to its levels stimulated with M.tb Ag85A in TBDM, PTB patients, their HHC, DM and HC.


TBDM: Tuberculosis with Diabetes Mellitus; HHC: Household Contacts; PTB: Pulmonary Tuberculosis; DM: Diabetes Mellitus; HC: Healthy Controls

Figure 4: IL-6 -174 G>C and -572G>C genotypes related to its levels stimulated with M.tb Ag85A in TBDM, PTB patients, their HHC, DM and HC. 
Citation: Meenakshi P, Ramya S, Madhavi Latha A, Lavanya J, Sumanlatha G (2017) Diverse Pattern of Cytokine Production, their Functional Association and mRNA Expression in Tuberculosis Patients with Diabetes Mellitus and their Household Contacts. J Microb Biochem Technol 9:143-150. doi: 10.4172/1948-5948.1000358

in PTB, $130.12 \mathrm{pg} / \mathrm{ml}, 88$ and 38 in PTB HHC and $119.3 \mathrm{pg} / \mathrm{ml}, 92$ and 26 in DM when compared to the HC. This indicates the importance of IL-6 cytokine gene for the risk analysis in HHC.

\section{mRNA expressions}

IL-1 $\beta$ mRNA expression was significantly low in TBDM (by 7 fold, $\mathrm{p}<0.008)$, PTB patients (5 fold, $\mathrm{p}<0.008)$, TBDM HHC (2.8 fold), PTB HHC (2.6 fold) and in DM (1.7 fold) when compared to HCs. During follow-up, statistically significant increase was observed at $6 \mathrm{M}$ vs. $0 \mathrm{M}$ $(\mathrm{p}<0.03)$ and $12 \mathrm{M}$ vs. $0 \mathrm{M}(\mathrm{p}<0.01)$ by 2.6 fold in TBDM. Significant difference was not observed at $4 \mathrm{M}$ in TBDM and at different stages of their follow up in PTB, PTB HHC and TBDM HHC.

IL-6 mRNA expression was statistically high in TBDM (by 12 fold, $\mathrm{p}<0.0009)$ PTB (8.9 fold, $\mathrm{p}<0.025)$, and without significant difference in TBDM HHC (4.8 fold), PTB HHC (4 fold) and DM (2.7 fold) when compared to HC. During follow-up, significant decrease was observed in TBDM ( $6 \mathrm{M}$ vs. $0 \mathrm{M}$ by 6.2 fold; $12 \mathrm{M}$ vs. $0 \mathrm{M}$ by 8.7 fold at $0 \mathrm{M}$ $(\mathrm{p}<0.008)$ and PTB (6M vs. $0 \mathrm{M}$ by 2 fold, $\mathrm{p}=0.038 ; 12 \mathrm{M}$ vs. $0 \mathrm{M}$ by 2.6 fold, $\mathrm{p}<0.037)$. Statistically significant difference was not observed in TBDM HHC and PTB HHC during their follow up (Figures 5 and 6).

\section{Discussion}

IL-1 $\beta$ production was low in TBDM compared to PTB without significant difference similar to a study in Japan where it was low in
TBDM patients and was in contrast to our study with respect to DM patients where almost similar IL- $1 \beta$ production was observed in TBDM and DM patients [26]. Low T cell proliferation and cytokine production in DM patients may be due to the intake of oral anti-diabetic drugs [27]. It was low in PTB patients in contrast to a Taiwan study where it was high [28]. A significant difference was observed in TBDM, TBDM HHC, PTB HHC and DM when compared to HC. Significant difference was not seen in M.tb H37Rv stimulated culture supernatants of TBDM and PTB patients similar to an Indonesian study where there was no difference in their IL- $1 \beta$ secretion and significantly large difference was observed between PTB patients and HCs with high levels in PTB. TBDM patients after M.tb stimulation have shown higher IL$1 \beta$ production similar to Indonesian study that may be due to severe hyperglycemia [29]. IL-1 $\beta$ secretion was found to be significantly high in TBDM compared to PTB patients similar to a study in Chennai [30]. There were no follow up studies with this cytokine secretion. The PTB patients with CC genotype of IL- $1 \beta+3954 \mathrm{C}>\mathrm{T}$ and TC genotype of IL- $1 \beta-511 \mathrm{C}>\mathrm{T}$ produce significantly low IL- $1 \beta$ when compared to the HCs. In comparison to our study, the two polymorphisms did not correlate with $M . t b$ stimulated production of IL- $1 \beta$ to the same extent in the PTB patients [31]. However, there were no functional correlation studies in the TBDM, TBDM HHC, PTB HHC and the DM.

A significant difference in IL- $1 \beta$ expression was observed in TBDM and PTB patients, we were the first to work on mRNA expression in
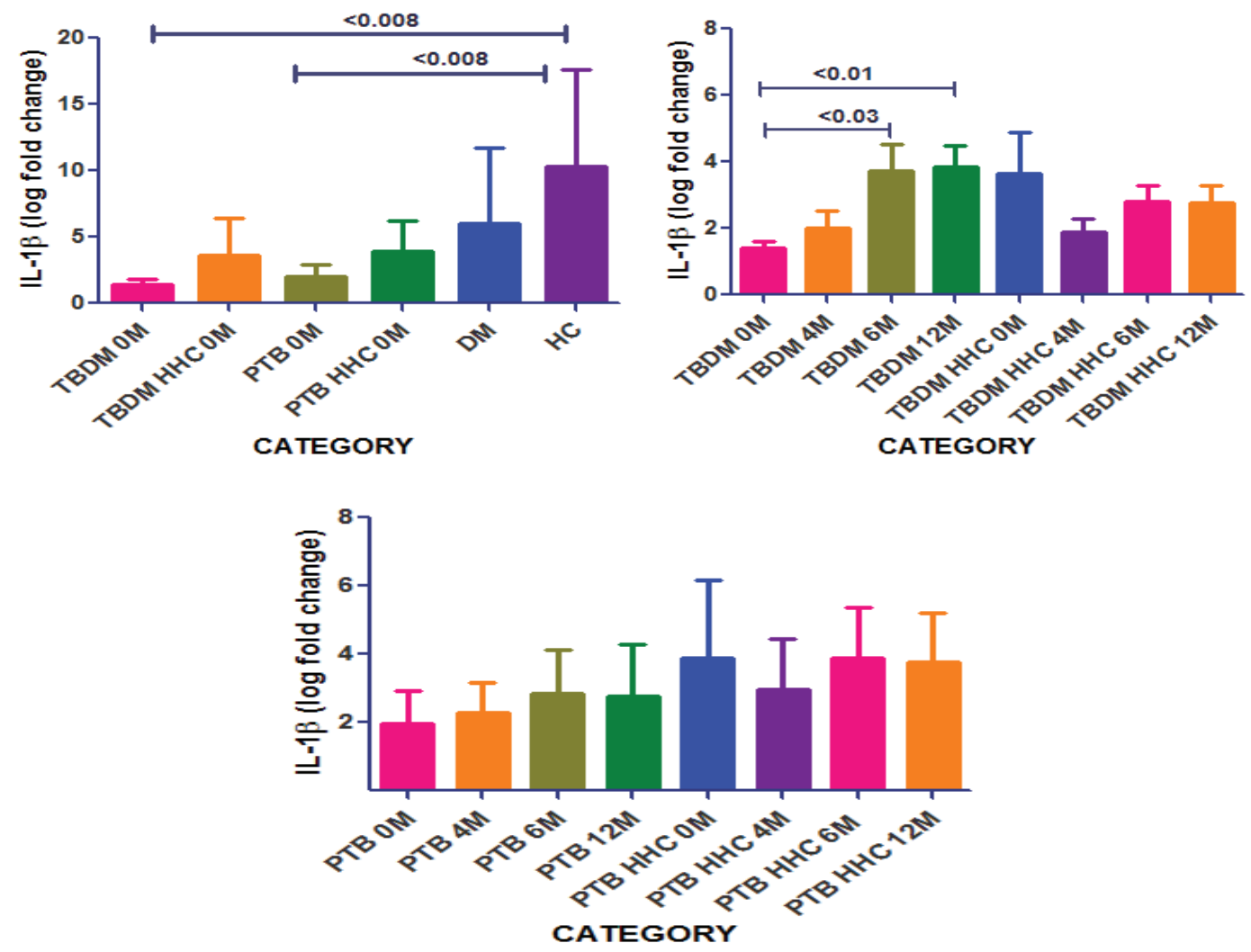

0M-0 month follow-up, $4 \mathrm{M}-4^{\text {th }}$ month follow-up, $6 \mathrm{M}-6^{\text {th }}$ month follow-up, $12 \mathrm{M}-12^{\text {th }}$ month follow-up, * $\mathrm{p}=0.05$ was considered statistically significant

Figure 5: IL-1 $\beta$ mRNA expression in response to M.tb Ag85A stimulation in TBDM, PTB patients, their HHC, DM and HC and during follow-up in TBDM, PTB patients and their $\mathrm{HHC}$. 
Citation: Meenakshi P, Ramya S, Madhavi Latha A, Lavanya J, Sumanlatha G (2017) Diverse Pattern of Cytokine Production, their Functional Association and mRNA Expression in Tuberculosis Patients with Diabetes Mellitus and their Household Contacts. J Microb Biochem Technol 9:143-150. doi: 10.4172/1948-5948.1000358
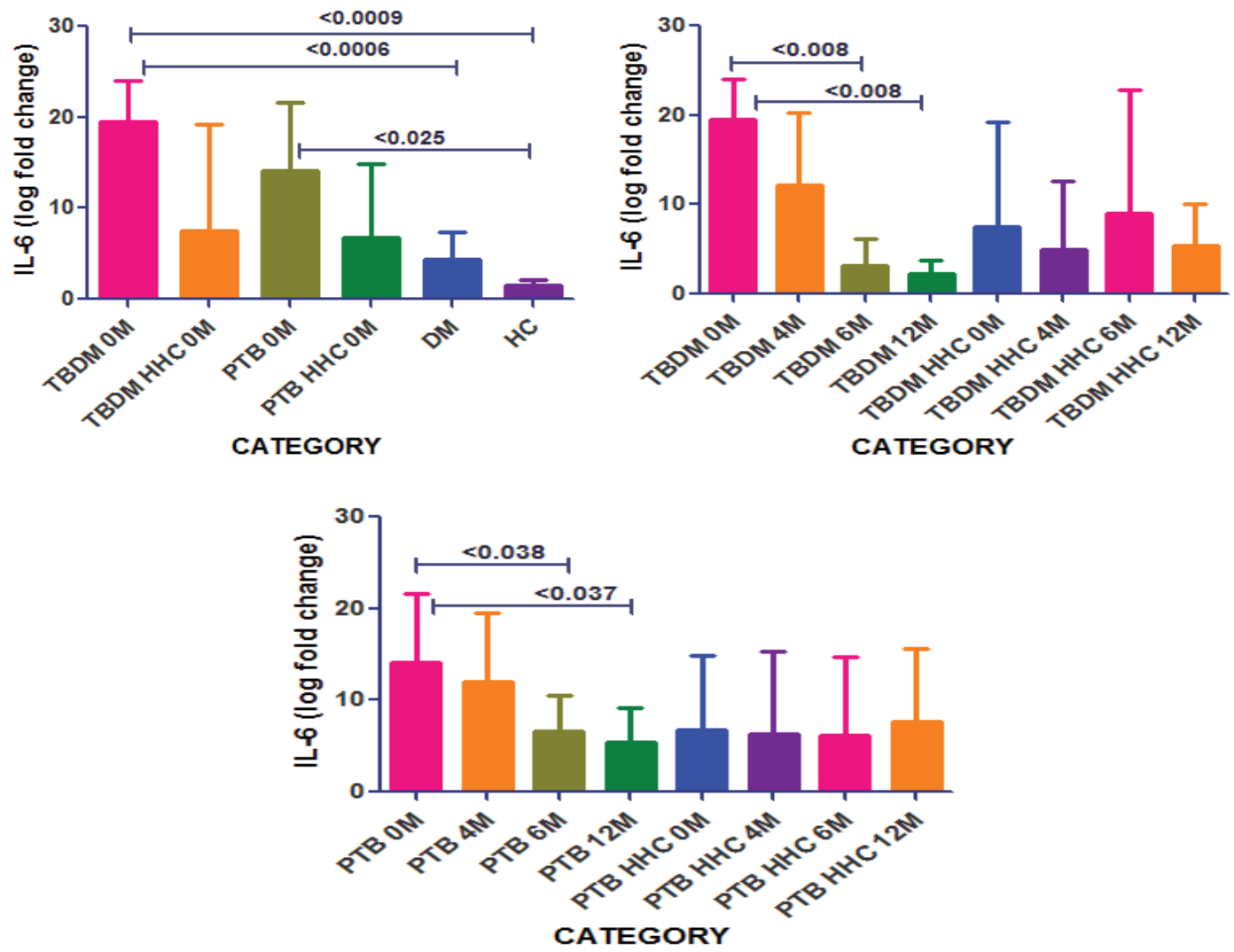

OM-0 month follow-up, $4 \mathrm{M}-4^{\text {th }}$ month follow-up, $6 \mathrm{M}-6^{\text {th }}$ month follow-up, $12 \mathrm{M}-12^{\text {th }}$ month follow-up, ${ }^{*} \mathrm{p}=0.05$ was considered statistically significant

Figure 6: IL-6 mRNA expression in response to M.tb Ag85A stimulation in TBDM, PTB patients, their HHC and DM vs. HC and during follow-up in TBDM, PTB patients and their $\mathrm{HHC}$.

TBDM and TBDM HHC. In this study, PTB patients and PTB HHC have not shown any significant difference during their follow up. IL-1 $\beta$ expression up-regulated in the alveolar macrophages of TB patients in a Chinese study and was significantly low in ESAT-6 stimulated PBMC of PTB patients when compared to the LTBI individuals, however statistical significance was not observed with respect to healthy controls $[32,33]$. IL-1 $\beta$ expression was low in the DM compared to HCs, which was contrary to a study where increased IL- $1 \beta$ mRNA was examined in the beta cells of DM patients with minimal or no expression [34].

The TBDM and their HHC have shown significantly low IL-6 production when compared to HCs without significant difference between TBDM and HCs similar to a Chennai study [30]. There were no reports in TBDM HHC to support our results. Its secretion was low in PTB when compared to HC in contrast to an Indonesian study where it was comparatively high [29]. A study by Jo et al. [34] and Ludmila et al. [5] reported that there was no statistical difference in the IL-6 production on stimulation with Ag85B and PPD in PTB patients and $\mathrm{HCs}$ and PTB HHC have not shown any variation from the $\mathrm{HCs}$ $[35,36]$. Our results were similar to a study where significantly higher levels were induced in PTB HHC when compared to PTB patients on proteomic analysis identification of immune-reactive $\mathrm{T}$ cell antigens [37]. IL-6 production significantly increased in plasma from active PTB patients and highly secreted after M.tb stimulation in central African population and specifically increased in pleural effusions in two different studies of Chinese population in contrast to our study [38]. This early response in the lungs might elicit initial restriction of mycobacterial growth. Decreased IL-6 expression may highlight its protective role in PTB patients. Low IL-6 production was observed in DM patients similar to Brazilian study; its elevation was reported in human adipocyte supernatants of both humans and Rabbits in USA and in individuals with Crohn's disease [39-41]. The CC genotype was considered as the high producer genotype in the PTB patients which was distinct from a study where IL-6 levels did not differ significantly between the $-174 \mathrm{G}>\mathrm{C}$ genotypes in the PTB patients and the HCs [42]. The G allele or GG genotype in the IL-6 gene promoter region (-174), was associated with high IL-6 production in TB patients which may have promoted TB by inhibiting production of other cytokines like TNF and IL-1 $\beta$ which was dissimilar to our study where GG genotype was associated with low IL-6 production in PTB patients $[43,44]$. Selvaraj et al., has not reported any significant association between the genotypes of IL-6 -174G $>$ C polymorphisms and production both in PTB and HCs unlike our study population [45]. Studies have not been reported in TBDM, TBDM HHC, PTB HHC and DM. There were no studies on the functional association of IL-6 $-572 \mathrm{G}>\mathrm{C}$ polymorphisms and its production.

IL-6 mRNA expression was high in TBDM patients when compared to HCs and decreased with treatment, however there were no studies in TBDM and TBDM HHC. To our knowledge, this was the first study on 
Citation: Meenakshi P, Ramya S, Madhavi Latha A, Lavanya J, Sumanlatha G (2017) Diverse Pattern of Cytokine Production, their Functional Association and mRNA Expression in Tuberculosis Patients with Diabetes Mellitus and their Household Contacts. J Microb Biochem Technol 9:143-150. doi: 10.4172/1948-5948.1000358

IL-6 mRNA expression in TBDM, TBDM HHC in response to M.tb Ag85A. IL-6 mRNA expression was significantly high in PTB patients when compared to $\mathrm{HC}$ which was in contrast to a Korean study [35] where it was similar in PTB patients and in HCs. Distinct results were reported in a study which has shown low IL-6 expression in the ESAT6 stimulated PBMCs of PTB patients when compared to the LTBI individuals without any difference in the HCs [33]. IL-6 expression was low in DM patients compared to the HCs dissimilar to other studies where it was elevated in DM patients [46]. Increased IL-6 mRNA was even observed in DM with induced oxidative stress and in the PBMC of metabolic syndrome patients and in T2DM patients [47-49]. TBDM patients responded to treatment at a similar pace in our study subjects which was in contrast to a retrospective study where it was found that TBDM patients who were on metformin, an anti-diabetic drug had fewer pulmonary cavities and significantly better survival. Metformin inhibited the intracellular growth of $M$. tuberculosis, restricted disease immunopathology and enhanced the efficacy of conventional anti-TB drugs in mice.

\section{Conclusion}

The mean cytokine levels were almost similar in the patients and household contacts without significant difference during their follow up. This might be due to the latent infection developed by the household contacts but due to their anti- inflammatory response, they might have not developed the disease. Our results were similar to certain studies, even discriminating results were reported which could be due to the different proliferation time of the different antigens used in different studies. The pro-inflammatory cytokine gene expression correlates with protective immunity against TB. Significantly low cytokine production and longer duration for treatment response was observed in the TBDM compared to PTB who were cured at an early stage. Presence of diabetes might be one of the reasons for the treatment delay in the TBDM. The IL- 6 cytokine gene was considered as a candidate gene and the most potential biomarker based on the ROC curve analysis with the highest sensitivity and specificity, hence may be used in the diagnostics for the analysis of risk in the household contacts. However, higher levels of pro inflammatory cytokine mRNA expression post infection signify a risk factor for developing active TB. Thus, our data suggests that the mechanisms that control the excessive inflammatory responses during $M . t b$ infection may have a critical role in the immunopathology of TB.

\section{References}

1. WHO, Global Tuberculosis Report 2014, World Health Organization, Geneva Switzerland, 2014.

2. IDF, IDF Diabetes Atlas Update Poster, IDF, 6th edition, 2014

3. Jeon CY, Murray MB (2008) Diabetes mellitus increases the risk of active tuberculosis: A systematic review of 13 observational studies. PLoS Med 5: e152.

4. Ruslami R, Aarnoutse RE, Alisjahbana B, Van Der Ven AJAM, Van Crevel R (2010) Implications of the global increase of diabetes for tuberculosis control and patient care. Trop Med Int Health 15:1289-1299.

5. Restrepo BI, Schlesinger LS (2014) Impact of diabetes on the natural history of tuberculosis. Diabetes Res Clin Pract 106:191-199.

6. Baker MA, Lin HH, Chang HY, Murray NB (2012) The risk of tuberculosis disease among persons with diabetes mellitus: A prospective cohort study. Clin Infect Dis 54: 818-825.

7. Jimenez-Corona ME, Cruz-Hervert LP, Garc'ı-Garc'ıa L (2013) Association of diabetes and tuberculosis: Impact on treatment and post-treatment outcomes. Thorax 68: 214-220.

8. Dooley KE, Chaisson RE (2009) Tuberculosis and diabetes mellitus: Convergence of two epidemics. Lancet Infect Dis 9: 737-746.
9. Riza AL, Pearson F, Ugarte-Gil Cet al. (2014) Clinical management of concurrent diabetes and tuberculosis and the implications for patient services. Lancet Diabetes Endocrinol 2: 740-753.

10. Ronacher K, Joosten SA, Van Crevel R, Dockrell HM, Walzl G, et al. (2015) Acquired immunodeficiency and tuberculosis: Focus on HIVIAIDS and diabetes mellitus. Immunol Rev 264: 121-137.

11. Thind D, Charalambous S, Tongman A, Churchyard G, Grant AD (2012) An evaluation of 'Ribolola': A household tuberculosis contact tracing programme in North West Province, South Africa. Int J Tuberc Lung Dis 16: 1643-1648.

12. Centers for Disease Control and Prevention Division of Tuberculosis Elimination (DTBE) in Cambodia, Household Contact Investigations (2010)

13. Morrison J, Pai M, Hopewell PC (2008) Tuberculosis and latent tuberculosis infection in close contacts of people with pulmonary tuberculosis in low-income and middle-income countries: A systematic review and meta-analysis. Lancet Infect Dis 8: 359-368.

14. Sinfield R, Nyirenda M, Haves S, Molyneux EM, Graham SM (2006) Risk factors for TB infection and disease in young childhood contacts in Malawi. Ann Trop Paediatr 26: 205-213.

15. Triasih R, Rutherford M, Lestari T, Utarini A, Robertson CF, et al. (2012) Contact investigation of children exposed to tuberculosis in South East Asia: A systematic review. J Trop Med.

16. Christopher DJ, Daley P, Armstrong L, James P, Gupta R, et al. (2010) Tuberculosis infection among Young Nursing Trainees in South India. PLoS ONE 5: e10408.

17. Harald G.W, Morten H (1992) The antigen 85 complex: A major secretion product of Mycobacterium tuberculosis. Microbiol Rev 56: 648-661.

18. Juffermans N.P, Florquin S, Camoglio L, Verbon, Kolk A.H, et al. (2000) Interleukin-1 signaling is essential for host defense during murine pulmonary tuberculosis. J Infect Dis 182: 902-908.

19. Dinarello CA (2006) The paradox of pro-inflammatory cytokines in cancer. Cancer Metastasis Rev 25: 307-313.

20. Marshall BG, Wangoo A, Cook HT, Shaw RJ (1996) Increased inflammatory cytokines and new collagen formation in cutaneous tuberculosis and sarcoidosis. Thorax 51: 1253-1261.

21. Saunders BM, Frank AA, Orme IM, Cooper AM (2000) Interleukin-6 induces early gamma interferon production in the infected lung but is not required for generation of specific immunity to Mycobacterium tuberculosis infection. Infect Immun 68: 3322-3326.

22. Kishimoto T, Hibi M, Murakami M, Narazaki M, Saito M, Taga T (1992) The molecular biology of interleukin 6 and its receptor. Ciba Found Symp 167: 5-16.

23. Kitamura A, Hasegawa G, Obayashi H, Kamiuchi K, Ishii M, et al. (2002) Interleukin-6 polymorphism $(-634 \mathrm{C} / \mathrm{G})$ in the promoter region and the progression of diabetic nephropathy in type 2 diabetes. Diabet Med 19: 10001005 .

24. Brull DJ, Montgomery HE, Sanders J, Dhamrait S, Luong L, et al. (2001) Interleukin- 6 gene $-174 \mathrm{~g}>\mathrm{c}$ and $-572 \mathrm{~g}>\mathrm{c}$ promoter polymorphisms are strong predictors of plasma interleukin-6 levels after coronary artery bypass surgery. Arterioscler Thromb Vasc Bio 21: 1458-1463.

25. Meenakshi P, Ramya S, Joshi L, Vijayalakshmi V, Sumanlatha G (2016) Effect of IFN-c, IL-12 and IL-10 cytokine production and mRNA expression in tuberculosis patients with diabetes mellitus and their household contacts. Cytokine 81: 127-136.

26. Karina Faccio M, Adroaldo L, Márcio Vinícius Fagundes D, Eduardo C, Carmen Silvana Araújo de O, et al. (2011) Immunomodulatory effects of oral antidiabetic drugs in lymphocyte cultures from patients with type 2 diabetes. J Bras Patol Med Lab 47: 43-48.

27. Su WL, Perng WC, Huang CH, Yang CY, Wu CP, et al. (2010) Association of reduced tumor necrosis factor alpha, gamma interferon and interleukin-1_(IL1 ) but increased IL-10 expression with improved chest radiography in patients with pulmonary tuberculosis. Clin Vaccine Immunol 17: 223-231.

28. Stalenhoef JE, Alisjahbana B, Nelwan EJ, Van-der venJongekrijq J, Ottenhoff $\mathrm{TH}$, et al. (2007) The role of interferon-gamma in the increased tuberculosis risk in type 2 diabetes mellitus. Eur J ClinMicrobiol Infect Dis 27: 97-103.

29. Kumar NP, Sridhar R, Banurekha VV, Jawahar MS, Fay MP, et al. (2013) Type 2 Diabetes mellitus coincident with pulmonary tuberculosis is associated with 
Citation: Meenakshi P, Ramya S, Madhavi Latha A, Lavanya J, Sumanlatha G (2017) Diverse Pattern of Cytokine Production, their Functional Association and mRNA Expression in Tuberculosis Patients with Diabetes Mellitus and their Household Contacts. J Microb Biochem Technol 9:143-150. doi: 10.4172/1948-5948.1000358

heightened systemic type 1, type 17 and other pro-inflammatory cytokines. Ann Am Thorac Soc 10: 441-449.

30. Robert J.W, Punita P, Martin L, Christina S.H, Geoffrey P, et al. (1999) Influence of polymorphism in the genes for the interleukin (IL)-1 receptor antagonist and IL-1 $\beta$ on tuberculosis. J Exp Med 189: 1863-1874.

31. Wang $\mathrm{CH}$, Kuo HP (2001) Nitric oxide modulates interleukin-1beta and tumour necrosis factor-alpha synthesis and disease regression by alveolar macrophages in pulmonary tuberculosis. Respirology 6: 79-84.

32. Bo Wu, Chunhong $\mathrm{H}$, Midori Kato M, Philip C, Clayberger $\mathrm{H}$, et al. (2007) Messenger rna expression of IL-8, FOXP3 and IL-12 $\beta$ differentiates latent tuberculosis infection from disease. J Immunol 178: 3688-3694.

33. Zhao G, Dharmadhikari G, Maedler K, Meyer-Hermann M (2014) Possible role of interleukin-1 $\beta$ in type 2 diabetes onset and implications for anti-inflammatory therapy strategies. PLoS Comput Biol 10: e1003798.

34. Jo EK, Kim HJ, Lim JH, Min D, Song Y, et al. (2000) Dysregulated production of interferon-G, interleukin-4 and interleukin-6 in early tuberculosis patients in response to antigen $85 \mathrm{~b}$ of Mycobacterium tuberculosis. Scand J Immunol 51: 209-217.

35. Ludmila VS, Ekaterina YS, Marina AT, Sergey DN, Alexandr AO, et al. (2014) Impairments of antigen-presenting cells in pulmonary tuberculosis. J Immunol Res: 793292.

36. Nemeth J, Winkler HM, Boeck L, Adegnika AA, Clement E, et al. (2011) Specific cytokine patterns of pulmonary tuberculosis in Central Africa. Clin Immunol 138: 50-59.

37. Yu Y, Zhang Y, Hu S, Jin D, Chen X, Jin Q, Liu H (2012) Different patterns of cytokines chemokines combined with IFN-y production reflects Mycobacterium tuberculosis infection and disease. PLoS ONE 7: e44944.

38. Foss NT, Foss-Freitas MC, Ferreira MAN, Cardili RN, Barbosa CMC, et al. (2007) Impaired cytokine production by peripheral blood mononuclear cells in type 1 diabetic patients. Diabetes Metab 33: 439-443.

39. Bao GV, Christopher SS, Katarina K, Wilmara Salgado P, Aloysius JK, et al. (2015) Chronic super antigen exposure induces systemic inflammation, elevated bloodstream endotoxin and abnormal glucose tolerance in rabbits: Possible role in diabetes. Mol Bio 6: e02554-14.

40. Pugazhendhi S, Jayakanthan K, Pulimood AB, Ramakrishna BS (2013) Cytokine gene expression in intestinal tuberculosis and Crohn's disease. Int $J$ Tuberc Lung Dis 17: 662-668.

41. Hu Yi, Linlin Wu, Dange Li, Qi Zhao, Weili Jiang, et al. (2015) Association between cytokine gene polymorphisms and tuberculosis in a Chinese population in Shanghai: A case-control study. BMC Immunol 16: 8.

42. Amirzargar AA, Rezaei N, Jabbari H, Danesh AA, Khosravi F, et al. (2016) Cytokine single nucleotide polymorphisms in Iranian patients with pulmonary tuberculosis. Eur Cytokine Netw 17: 84-89.

43. Azad AK, Sadee W, Schlesinger LS (2012) Innate immune gene polymorphisms in tuberculosis. Infect Immun 80: 3343-3359.

44. Selvaraj P, Alagarasu K, Harishankar M, Vidyarani M, NishaRajeswari D, et al. (2008) Cytokine gene polymorphisms and cytokine levels in pulmonary tuberculosis. Cytokine 43: 26-33.

45. Tsiotra PC, Tsigos C, Yfanti E, Anastasiou E, Vikentiou M, et al. (2007) TNFalpha and IL-6 mRNA expression is increased in mononuclear cells from type 2 diabetic women. Horm Metab Res 39: 758-63.

46. Zhang L, Zalewski A, Liu Y, Mazurek T, Cowan S, et al. (2003) Diabetesinduced oxidative stress and low-grade inflammation in porcine coronary arteries. Circulation 108: 472-478.

47. Hardy OT, Ciccarelli C, Hayman LL, Wiecha J (2012) Increased Toll-like receptor (TLR) mRNA expression in monocytes is a feature of metabolic syndrome in adolescents. Paediatric Obesity 8: e19-23.

48. Scheele C, Nielsen S, Kelly M, Broholm C, Nielsen AR, et al. (2012) Satellite cells derived from obese humans with type 2 diabetes and differentiated into myocytes in vitro exhibit abnormal response to IL-6. PLoS ONE 7: e39657.

49. Getahun A, Daniel FH (2016) Immunotherapy for tuberculosis: Future prospects. Immunotargets Ther 5: 37-45. 